\title{
Blood-brain barrier leakage is more widespread in patients with cerebral small vessel disease
}

Citation for published version (APA):

Zhang, C. E., Wong, S. M., van de Haar, H. J., Staals, J., Jansen, J. F. A., Jeukens, C. R. L. P. N., Hofman, P. A. M., van Oostenbrugge, R. J., \& Backes, W. H. (2017). Blood-brain barrier leakage is more widespread in patients with cerebral small vessel disease. Neurology, 88(5), 426-432.

https://doi.org/10.1212/WNL.0000000000003556

Document status and date:

Published: 31/01/2017

DOI:

10.1212/WNL.0000000000003556

Document Version:

Publisher's PDF, also known as Version of record

Document license:

Taverne

Please check the document version of this publication:

- A submitted manuscript is the version of the article upon submission and before peer-review. There can be important differences between the submitted version and the official published version of record.

People interested in the research are advised to contact the author for the final version of the publication, or visit the DOI to the publisher's website.

- The final author version and the galley proof are versions of the publication after peer review.

- The final published version features the final layout of the paper including the volume, issue and page numbers.

Link to publication

\footnotetext{
General rights rights.

- You may freely distribute the URL identifying the publication in the public portal. please follow below link for the End User Agreement:

www.umlib.nl/taverne-license

Take down policy

If you believe that this document breaches copyright please contact us at:

repository@maastrichtuniversity.nl

providing details and we will investigate your claim.
}

Copyright and moral rights for the publications made accessible in the public portal are retained by the authors and/or other copyright owners and it is a condition of accessing publications that users recognise and abide by the legal requirements associated with these

- Users may download and print one copy of any publication from the public portal for the purpose of private study or research.

- You may not further distribute the material or use it for any profit-making activity or commercial gain

If the publication is distributed under the terms of Article $25 \mathrm{fa}$ of the Dutch Copyright Act, indicated by the "Taverne" license above, 


\section{Blood-brain barrier leakage is more widespread in patients with cerebral small vessel disease}

C. Eleana Zhang, MD* Sau May Wong, MSc* Harm J. van de Haar, MSc

Julie Staals, MD, PhD Jacobus F.A. Jansen, PhD Cécile R.L.P.N. Jeukens, $\mathrm{PhD}$

Paul A.M. Hofman, MD

Robert J. van

Oostenbrugge, MD, $\mathrm{PhD}$

Walter H. Backes, PhD

Correspondence to

Dr. Zhang:

eleana.zhang@mumc.nl

Editorial, page 420

Supplemental data at Neurology.org

\section{ABSTRACT}

Objective: As blood-brain barrier (BBB) dysfunction may occur in normal aging but may also play a pivotal role in the pathophysiology of cerebral small vessel disease (cSVD), we used dynamic contrast-enhanced (DCE)-MRI to quantify the rate and the spatial extent of BBB leakage in patients with cSVD and age- and sex-matched controls to discern cSVD-related BBB leakage from aging-related leakage.

Methods: We performed structural brain MRI and DCE-MRI in 80 patients with clinically overt cSVD and 40 age- and sex-matched controls. Using the Patlak pharmacokinetic model, we calculated the leakage rate. The mean leakage rate and relative leakage volume were calculated using noise-corrected histogram analysis. Leakage rate and leakage volume were compared between patients with cSVD and controls for the normal-appearing white matter (NAWM), white matter hyperintensities (WMH), cortical gray matter (CGM), and deep gray matter.

Results: Multivariable linear regression analyses adjusting for age, sex, and cardiovascular risk factors showed that the leakage volume of the NAWM, WMH, and CGM was significantly larger in patients with cSVD compared with controls. No significant difference was found for leakage rate in any of the tissue regions.

Conclusion: We demonstrated a larger tissue volume with subtle BBB leakage in patients with CSVD than in controls. This was shown in the NAWM, WMH, and CGM, supporting the generalized nature of cSVD. Neurology ${ }^{\circledR}$ 2017;88:426-432

\section{GLOSSARY}

BBB = blood-brain barrier; $\mathbf{C G M}=$ cortical gray matter; $\mathbf{C S V D}=$ cerebral small vessel disease; $\mathbf{D C E}$ = dynamic contrastenhanced; DGM = deep gray matter; DST = dynamic scan time; FLAIR = fluid-attenuated inversion recovery; FOV = field of view; $\mathbf{m V C l}=$ mild vascular cognitive impairment; $\mathbf{N A W M}=$ normal-appearing white matter; $\mathbf{R O I}=$ region of interest; SENSE = sensitivity encoding for MRI; TE = echo time; TR = repetition time; $\mathbf{W M H ~}=$ white matter hyperintensities.

Cerebral small vessel disease (cSVD) underlies debilitating clinical disorders including lacunar stroke and vascular cognitive impairment. ${ }^{1-3}$ The pathophysiology is unclear but blood-brain barrier $(\mathrm{BBB})$ dysfunction has been proposed as one of the mechanisms. ${ }^{2}$

$\mathrm{BBB}$ dysfunction occurs in normal aging but may also play a pivotal role in CSVD. Extravasation of blood components may cause local vascular changes and diffuse brain tissue damage. ${ }^{4-7}$ With the development of dynamic contrast-enhanced (DCE) MRI, several studies aimed to measure BBB permeability in patients with cSVD. Semiquantitative contrast-enhanced studies described the prolonged MRI signal enhancement of a contrast agent in the white matter, and attributed this to increased BBB permeability in lacunar stroke patients. ${ }^{89}$ Moreover, BBB permeability in the white matter was found to be quantitatively increased in patients with vascular cognitive impairment. ${ }^{10}$ To distinguish cSVD-related BBB leakage from normal aging-related $\mathrm{BBB}$ breakdown, quantitative techniques are highly preferred. However, quantitative data of BBB permeability in patients with cSVD are scarce and knowledge on the spatial extent of BBB leakage in cSVD is lacking. ${ }^{1}$

*These authors contributed equally to this work.

From the Departments of Neurology (C.E.Z., J.S., R.J.v.O.) and Radiology \& Nuclear Medicine (S.M.W., H.J.v.d.H., J.F.A.J., C.R.L.P.N.J., P.A. M.H., W.H.B.), Maastricht University Medical Centre; Cardiovascular Research Institute Maastricht (CARIM) (C.E.Z., R.J.v.O.); and School for Mental Health and Neuroscience (MHeNS) (C.E.Z., S.M.W., H.J.v.d.H., J.S., J.F.A.J., P.A.M.H., R.J.v.O., W.H.B.), Maastricht, the Netherlands.

Go to Neurology.org for full disclosures. Funding information and disclosures deemed relevant by the authors, if any, are provided at the end of the article. 
Dual-time resolution DCE-MRI enables measurement of contrast agent in the microvascular blood space and detection of the extravasation of relatively low concentrations of a contrast agent through the BBB. By using DCE-MRI combined with pharmacokinetic modeling, we aim to provide accurate, quantitative data of BBB leakage rate and the spatial extent (volume) of BBB leakage in patients with cSVD compared with a control group. To have a clinical spectrum linked to cSVD, we included patients with lacunar stroke and patients with vascular cognitive impairment.

METHODS Study population. We included patients with clinically overt CSVD and age- and sex-matched controls. Patients with cSVD consisted of patients with consecutive first-ever lacunar stroke and patients with mild vascular cognitive impairment (mVCI) who consented to participate in the study. Participants were included from the Maastricht University Medical Centre and Zuyderland Hospital, the Netherlands, between April 2013 and December 2014. Lacunar stroke patients were recruited from the stroke unit. Lacunar stroke was defined as an acute stroke syndrome with a compatible recent small subcortical infarct on brain MRI. If no such lesion was visible on imaging, established criteria for lacunar stroke syndrome were used. ${ }^{11,12}$ Exclusion criteria include a potential cardiac embolic source (e.g., atrial fibrillation) or symptomatic carotid stenosis of $\geq 50 \% .{ }^{13}$ Stroke patients were included at least 3 months poststroke to avoid acute stroke changes. ${ }^{14}$ Patients with $\mathrm{mVCI}$ were recruited from the outpatient clinic of the Department of Neurology and from the Memory Clinic. Criteria of mVCI were met when patients had (1) subjective complaints of cognitive functioning, (2) objective cognitive impairment in at least one cognitive domain at neuropsychological testing, (3) a Clinical Dementia Rating score of $\leq 1$ and a Mini-Mental State Examination score of $\geq 20$, and (4) vascular lesions on brain MRI that suggest a link between the cognitive deficit and cSVD $^{15}$ : moderate to severe white matter hyperintensities (WHM; Fazekas score deep $>1$ or periventricular $>2$ ) or mild WMH (Fazekas score deep $=1$ or periventricular $=2$ ) combined with lacunes or microbleeds. ${ }^{16}$

Age- and sex-matched controls were recruited from the outpatient clinic of the Department of Neurology. We included one control per 2 patients with cSVD. Controls were defined as participants with no overt cerebrovascular diseases and no cognitive impairment. Most of them had lumbar radicular syndrome or peripheral neuropathies. Additional exclusion criteria for all participants include neurodegenerative diseases, multiple sclerosis, epilepsy, systemic inflammatory diseases, alcohol abuse, psychiatric disorders or use of medication that may influence the accuracy of neuropsychological testing, and the presence of a contraindication for MRI (e.g., pacemaker, claustrophobia, or contrast allergy).

Characteristics of all participants were recorded including age, sex, and the presence of cardiovascular risk factors including hypertension (history of hypertension or use of blood pressure-lowering drugs), hypercholesterolemia (history of hypercholesterolemia or use of statin), diabetes mellitus (history of diabetes mellitus or use of blood sugar-lowering drugs), smoking (current smoking), and body mass index (current weight by the square of the current length).
Standard protocol approvals, registrations, and patient consents. The Medical Ethics Committee of the Maastricht University Medical Centre approved the study. All participants were included after providing written informed consent. This study is registered on trialregister.nl (NTR number NTR3786).

Structural MRI. All participants underwent structural brain MRI (3.0T). A T1-weighted sequence and T2-weighted fluidattenuated inversion recovery (FLAIR) sequence were used for anatomic reference and detection of $\mathrm{WMH}$, respectively. MRI sequence parameters are provided in the supplemental data at Neurology.org.

DCE-MRI. Dual-time resolution DCE-MRI consisted of 2 integrated dynamic sequences with different dynamic scan time (DST): the fast and the slow sequence. ${ }^{17}$ Both sequences were saturation recovery gradient-recalled sequences with a flip angle of $10^{\circ}$ for the excitation pulse and had a $90^{\circ}$ nonselective saturation prepulse with a time delay of 120 milliseconds. First, precontrast scans of both sequences were acquired prior to bolus injection. Subsequently, the fast sequence was applied (DST 3.2 seconds, repetition time [TR]/echo time [TE] 5.6/2.5 milliseconds, field of view [FOV] $256 \times 200 \times 50 \mathrm{~mm}^{3}$, voxel size $2 \times 2 \times$ $5 \mathrm{~mm}, 29$ volumes, sensitivity encoding for MRI [SENSE] 2) during bolus injection. Hereafter, the slow sequence was performed (DST 30.5 seconds, TR/TE 5.6/2.5 milliseconds, FOV $256 \times 256 \times 100 \mathrm{~mm}^{3}$, voxel size $1 \times 1 \times 2 \mathrm{~mm}, 45$ volumes, SENSE 2). Both sequences were centered on the periventricular region. The contrast agent (gadobutrol $1.0 \mathrm{mmol} /$ $\mathrm{mL} ; 0.1 \mathrm{mmol} / \mathrm{kg}$ body weight, range $5-10 \mathrm{mmol}$ per person) was injected in the antecubital vein at a rate of $3 \mathrm{~mL} / \mathrm{s}$ using a power injector. To convert the contrast-enhanced signal intensities to concentrations in tissue, T1 mapping ${ }^{18}$ was performed prior to contrast agent administration and dynamic imaging.

Brain segmentation. Gray and white matter were segmented on the T1-weighted images using dedicated imaging software $\left(\right.$ Freesurfer $\left.{ }^{19}\right)$. Subsequently, WMHs were segmented on the FLAIR image to differentiate between normal and abnormalappearing white matter using a semiautomated segmentation tool. ${ }^{20}$ Moreover, infarcts were visually identified and excluded from the WMHs. FLAIR and T1-weighted image were coregistered using FSL (v5.0) ${ }^{21}$ and the following tissue regions of interest (ROIs) were selected: normal-appearing white matter (NAWM), WMHs, cortical gray matter (CGM), and deep gray matter (DGM).

Pharmacokinetic modeling. The concentration of contrast agent in tissue was calculated by using the relative signal change and T1 mapping. ${ }^{18}$ The vascular input function was derived from the superior sagittal sinus. ${ }^{22}$ To convert the signal intensity curve to concentration, a calibration curve was obtained from phantoms with various in vitro contrast agent concentrations. Subsequently, the graphical Patlak model was used to estimate the leakage rate in terms of the transfer constant $\mathrm{K}_{\mathrm{i}}\left(\right.$ minute $\left.^{-1}\right)$ and the blood plasma volume in terms of the fractional intravascular space $\left(\mathrm{v}_{\mathrm{P}}\right) .^{23}$

$\mathrm{K}_{\mathrm{i}}$ and $\mathrm{v}_{\mathrm{P}}$ were obtained from the slope and intercept, respectively, of the Patlak plot. In this way, the concentration time course of the extravasating contrast agent, i.e., leakage, was discerned from the intravascular concentration. The leakage rate $\mathrm{K}_{\mathrm{i}}$ can be understood as the initial concentration increase per time unit (speed) in the tissue relative to the blood concentration. This rate is estimated from the increase in the tissue concentration over time from a pharmacokinetic model in which reuptake of contrast agent by the blood is neglected.

Histogram analysis. The $\mathrm{K}_{\mathrm{i}}$ and $\mathrm{v}_{\mathrm{P}}$ were determined in a voxelwise manner. For the $K_{i}$ values, a histogram was calculated for 
each ROI. The $\mathrm{K}_{\mathrm{i}}$ histogram had positive, zero, and negative $\mathrm{K}_{\mathrm{i}}$ values and appeared skewed towards more positive $\mathrm{K}_{\mathrm{i}}$ values (figure 1). In the case of subtle leakage, $K_{i}$ values had an overlap with noise. The noise could be observed by the presence of negative values in the histogram. To correct the leakage for noise, the positive noise distribution was estimated by mirroring the negative $\mathrm{K}_{\mathrm{i}}$ value distribution and subtracting

Figure 1 Histogram analysis

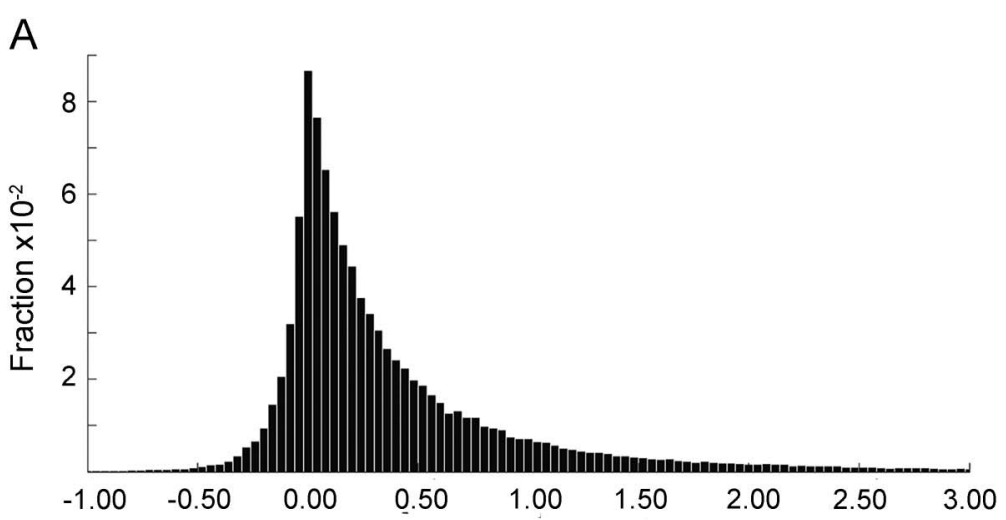

B

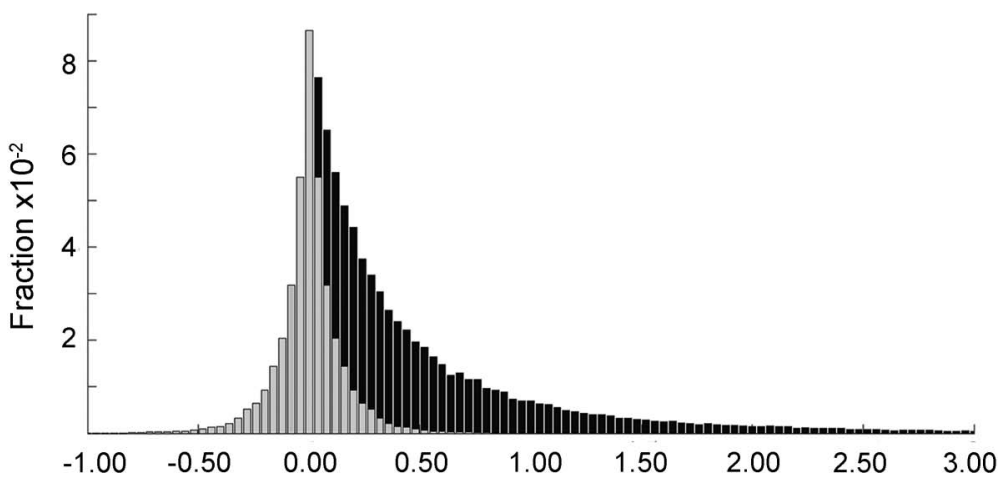

C

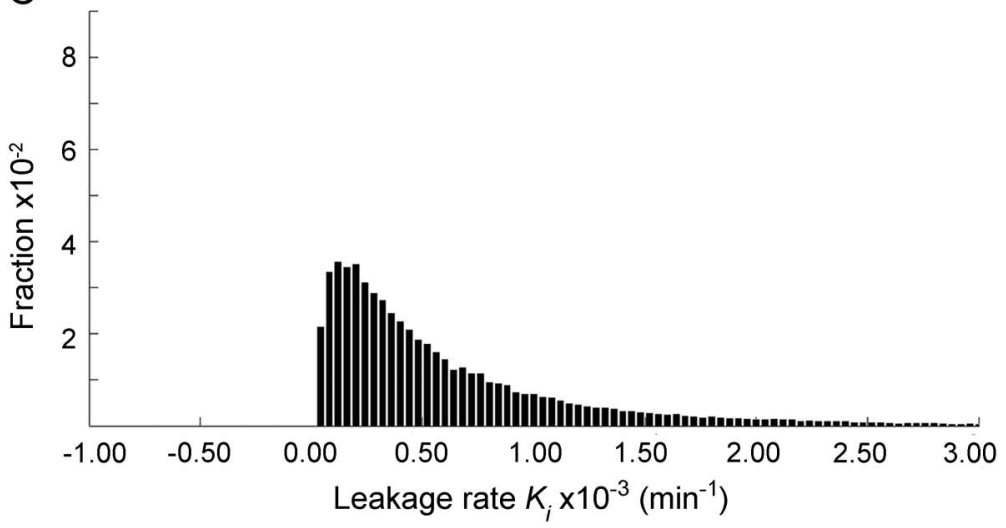

An overview of the noise estimation method using bar graphs. Here, the $x$-axis shows the leakage rate $\left(\mathrm{K}_{\mathrm{i}}\right)$ and the $\mathrm{y}$-axis the fraction (i.e., the percentage divided by 100) of brain tissue (voxels) with this leakage rate. In (A), a distribution of the leakage rate values are shown with positive, zero, and negative values, which appears skewed towards more positive values. To estimate the noise distribution, the negative values are assumed to be noise. By mirroring these negative bins around zero, a total noise distribution (gray bins) was estimated (B). Subtracting this noise distribution ( $B$, gray bins) from the original distribution ( $B$, black bins) results in a (positive) leakage rate distribution corrected for noise ( $C$, black bins). The leakage volume is calculated as the area under the bar graph of the leakage rate distribution corrected for noise (C, black bins). this from the original $K_{\mathrm{i}}$ distribution (figure 1). ${ }^{17}$ This resulted in a histogram of (positive) $K_{i}$ values reflecting the detectable leakage rates. Descriptive values from this (positive) histogram were derived: the mean $K_{i}$, by taking the average of $K_{i}$ values, indicating the magnitude of the (detectable) leakage rate, and the fractional volume of leakage $\left(\mathrm{v}_{\mathrm{L}}\right)$, which was the remaining area under the histogram curve, representing the relative volume of leakage with respect to the tissue volume of interest. Note that $\mathrm{v}_{\mathrm{L}}$ is a volume measure and represents a conceptually different measure of the leakage, namely the spatial extent, whereas the leakage rate $\mathrm{K}_{\mathrm{i}}$ is a magnitude measure. These calculations were performed for all ROIs. For the blood plasma volume, the mean value over each ROI was taken. For the purpose of conceptual clarity, we use the term leakage rate (reflected in the transfer constant $\mathrm{K}_{\mathrm{i}}$ ) for the rate of contrast leakage across the vessel wall and leakage volume (reflected in $\mathrm{v}_{\mathrm{L}}$ ) for the fractional volume of leaky brain tissue as the 2 quantitative measures of BBB leakage.

Statistical analysis. Independent Student $t$ test and $\chi^{2}$ test were used for comparing clinical characteristics between patients with cSVD and controls.

The leakage rate and leakage volume were examined and compared between patients with CSVD and controls using univariable linear regression analysis, with mean leakage rate, leakage volume, and blood plasma volume, respectively, as dependent variable, and group (cSVD vs controls) as independent variable. Subsequently, multivariable linear regression analysis was performed with age, sex, group (cSVD vs controls), and cardiovascular risk factors as independent variables. This was performed for all ROIs. Similar analyses were performed for the blood plasma volume. Furthermore, we also compared the subgroups lacunar stroke and $\mathrm{mVCI}$ with regard to leakage rate and leakage volume using univariable and multivariable linear regression analysis adjusted for age, sex, and cardiovascular risk factors. Statistical significance was inferred at $p<0.05$. We controlled for multiple testing according to the Benjamin-Hochberg procedure, using a false discovery rate of $0.10 .^{24}$ All statistical analyses were performed using commercial software (SPSS 22; SPSS Inc., Chicago, IL).

RESULTS We included 80 patients with cSVD and 40 age- and sex-matched controls. We excluded 4 participants due to unsuccessful imaging or image artefacts, leaving 77 patients with cSVD (43 patients with lacunar stroke and 34 patients with $\mathrm{mVCI}$ ) and 39 controls suitable for analysis. An example of a leakage map of a patient with cSVD is displayed in figure 2. Clinical characteristics of these participants are presented in table 1 (additional data are presented in table e-1). Hypercholesterolemia and current smoking were significantly more prevalent in patients compared with controls.

Table 2 provides an overview of the quantitative results and includes comparison between the 2 groups.

Leakage rate. Univariable and multivariable linear regression analysis showed no significant differences for leakage rate between patients with CSVD and controls in any of the ROIs.

Leakage volume. Univariable regression analysis showed a significantly higher leakage volume in the WMH and CGM of patients with cSVD compared 

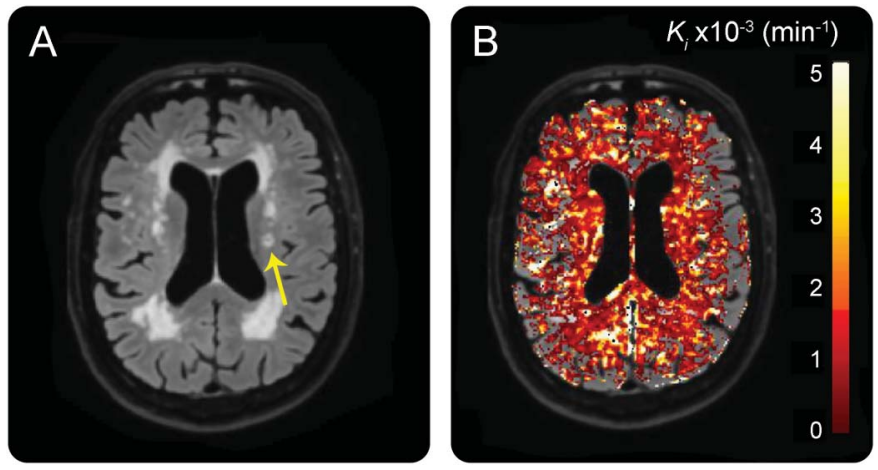

(A) Example of a FLAIR image and (B) a leakage map of one patient with cerebral small vessel diseasewith extensive white matter hyperintensities and a lacunar infarct (arrow in A). The leakage is diffuse throughout the brain

with controls. In addition, multivariable regression analysis showed a significantly higher leakage volume in patients with cSVD in the NAWM, WMH, and CGM. This higher leakage volume is mainly observed in the range of the low leakage rates (figure 3).

Blood plasma volume. Patients with cSVD showed a tendency to have lower blood plasma volume values than did controls in all tissue regions. However, these differences were not significant.

In the multivariable analyses of the 3 outcome measures, none of the cardiovascular risk factors showed consistent independent association with BBB leakage, except for hypercholesterolemia, which is associated with a lower leakage volume in the NAWM, CGM, and DGM (data not shown).

Comparison between the 2 patient groups using univariable and multivariable analysis showed no significant differences in leakage volume and a higher leakage rate in the DGM and WMH in lacunar stroke patients compared with mVCI patients (table e-2).

DISCUSSION In this study, we found that patients with cSVD exhibit a larger volume of subtle leakage

\begin{tabular}{|c|c|c|c|}
\hline \multirow[t]{2}{*}{ Table 1} & \multicolumn{3}{|c|}{$\begin{array}{l}\text { Characteristics of patients with cerebral small vessel disease (cSVD) } \\
\text { and controls }\end{array}$} \\
\hline & & Patients with cSVD $(n=77)$ & Controls $(n=39)$ \\
\hline \multicolumn{2}{|c|}{ Age, $y$, mean (SD) } & $70(11)$ & $69(12)$ \\
\hline \multicolumn{2}{|c|}{ Male, n (\%) } & $46(60)$ & $23(59)$ \\
\hline \multicolumn{2}{|c|}{ Hypertension, n (\%) } & $49(64)$ & $18(46)$ \\
\hline \multicolumn{2}{|c|}{ Hypercholesterolemia, n (\%) ${ }^{\mathrm{a}}$} & $50(65)$ & $13(33)$ \\
\hline \multicolumn{2}{|c|}{ Diabetes, n (\%) } & $12(16)$ & $4(10)$ \\
\hline \multicolumn{2}{|c|}{$\mathrm{BMI}, \mathrm{kg} / \mathrm{m}^{2}$, mean (SD) } & $26(4)$ & 27 (3) \\
\hline \multicolumn{2}{|c|}{ Smoking, \%a } & $19(25)$ & $3(8)$ \\
\hline
\end{tabular}

Abbreviation: $\mathrm{BMI}=$ body mass index.

${ }^{a} p<0.05$ when comparing patients with cSVD and controls. in the NAWM, CGM, and WMH compared with controls, whereas leakage rate did not differ. This finding indicates that spatial extent of leaky brain tissue is significantly larger in patients with cSVD than controls.

The current approach was tailored to measure very subtle BBB leakage rates with values towards or in the noise range. Therefore a dual-time resolution DCE-MRI technique was applied with 2 different time resolutions to adequately discern the early recirculation of the contrast agent from the later washout, a relatively long measurement time, and a dedicated analysis method that corrected for the inherent noise. Introducing the concept of leakage volume, it appeared that the differences in leakage between patients with cSVD and controls manifested particularly in an increased spatial extent of very subtle leakage. Differences between patients with CSVD and controls manifested for the very low leakage rate values, which appeared more prominent in CSVD, and not the average of (locally) high leakage rate values (figure 3 ). The values of these low leakage rates were in the order of the noise level, and could only be detected due to the methodologic optimization (noise filtering).

Our finding that patients with CSVD have a larger tissue volume showing BBB leakage is in line with the assumption that cSVD is a disease with diffuse, endothelial damage. ${ }^{1}$ Although subtle, the endothelial failure was detectable and appears to extend to the white matter as well as CGM. cSVD was primarily considered a white matter disease but recent studies show that CGM is also involved. ${ }^{2,19,20}$ Our results are in accordance with these advanced insights and underline the importance of investigating both cortical and white matter involvement in CSVD.

BBB leakage rate was not higher in patients with cSVD compared with controls. This may reflect the subtle nature of BBB dysfunction, which is supported by recent neuropathologic studies, which showed that markers associated with BBB integrity were reduced, but extravasation of large plasma proteins was not significantly increased in cSVD. ${ }^{25,26}$ Apparently, BBB dysfunction is present but possibly only small molecule leakage can be measured.

In contrast to our finding, an earlier study showed stronger BBB leakage rates in the white matter of patients with VCI compared with controls, using DCE-MRI and pharmacokinetic modeling. ${ }^{10}$ However, their controls were not matched by age, nor were the results corrected for age, and the investigated group also included patients with cortical stroke. As aging is thought to be associated with an increase in BBB permeability, the difference in age criteria of the control group may explain the different observations and underline the importance of age-matching. ${ }^{4,27}$ Furthermore, our finding that leakage rate does not 


\begin{tabular}{|c|c|c|c|c|c|c|}
\hline \multirow[t]{2}{*}{ Table 2} & eakage volume, and & ma volume & s with cer & all vesse & cSVD) an & \\
\hline & Patients with cSVD & Controls & \multicolumn{2}{|c|}{ Univariable } & \multicolumn{2}{|c|}{ Multivariable } \\
\hline \multicolumn{7}{|l|}{ NAWM } \\
\hline $\mathrm{K}_{\mathrm{i}}\left(10^{-3} \mathrm{~min}^{-1}\right)$ & $0.97(0.04)$ & $1.05(0.05)$ & -0.119 & 0.20 & -1.960 & 0.05 \\
\hline$v_{p}\left(10^{-2}\right)$ & $1.68(0.10)$ & $2.30(0.45)$ & -0.163 & 0.08 & -0.156 & 0.13 \\
\hline \multicolumn{7}{|l|}{ WMH } \\
\hline $\mathrm{K}_{\mathrm{i}}\left(10^{-3} \mathrm{~min}^{-1}\right)$ & $0.85(0.03)$ & $0.87(0.05)$ & -0.042 & 0.66 & -0.086 & 0.41 \\
\hline$v_{L}\left(10^{-2}\right)$ & $45.5(2.31)$ & $35.2(3.00)$ & 0.239 & $0.01^{a, b}$ & 0.329 & $0.001^{a, b}$ \\
\hline$v_{L}\left(10^{-2}\right)$ & $20.7(1.56)$ & $14.7(1.76)$ & 0.214 & $0.02^{a, b}$ & 0.313 & $0.002^{a, b}$ \\
\hline$v_{p}\left(10^{-2}\right)$ & $3.56(0.19)$ & $4.39(0.53)$ & -0.165 & 0.08 & -0.162 & 0.12 \\
\hline \multicolumn{7}{|l|}{ DGM } \\
\hline $\mathrm{K}_{\mathrm{i}}\left(10^{-3} \mathrm{~min}^{-1}\right)$ & $1.06(0.04)$ & $1.11(0.06)$ & -0.070 & 0.45 & -0.110 & 0.29 \\
\hline$v_{L}\left(10^{-2}\right)$ & 3з.3 (2.14) & 30.4 (3.61) & 0.068 & 0.47 & 1.77 & 0.08 \\
\hline$v_{p}\left(10^{-2}\right)$ & $3.33(0.20)$ & $4.09(0.57)$ & -0.142 & 0.13 & -0.121 & 0.25 \\
\hline
\end{tabular}

Abbreviations: $\mathrm{CGM}=$ cortical gray matter; $\mathrm{DGM}=$ deep gray matter; $\mathrm{K}_{\mathrm{i}}=$ leakage rate; $\mathrm{NAWM}=$ normal-appearing white matter; $\mathrm{v}_{\mathrm{L}}=$ leakage volume; $\mathrm{v}_{\mathrm{p}}=$ blood plasma volume; $\mathrm{WMH}=$ white matter hyperintensities.

Values are mean (standard error). Multivariable linear regression analysis with $\mathrm{Ki}, \mathrm{v}_{\mathrm{L}}$, and $\mathrm{v}_{\mathrm{p}}$ as dependent variable and age, sex, group, and cardiovascular risk factors as independent variables.

a Significant.

${ }^{\mathrm{b}} \mathrm{p}$ Values that remain statistically significant after multiple comparison correcting for the testing of 4 tissue regions of interest.

differ between patients with cSVD and age-matched controls may suggest that changes in leakage rate are aging-related processes, and are not specifically cSVD-related. Other studies showed increased contrast enhancement in the white matter, suggesting stronger leakage in lacunar stroke patients compared with cortical stroke patients and with controls. ${ }^{8,9}$ Objective comparisons with our study remain difficult, as control groups were different or these 2 previous studies used semiquantitative analysis methods in which intravascular and extravascular enhancement were not separated and effects may be due to either

Figure 3 Leakage rate in patients with cerebral small vessel disease (cSVD) and controls

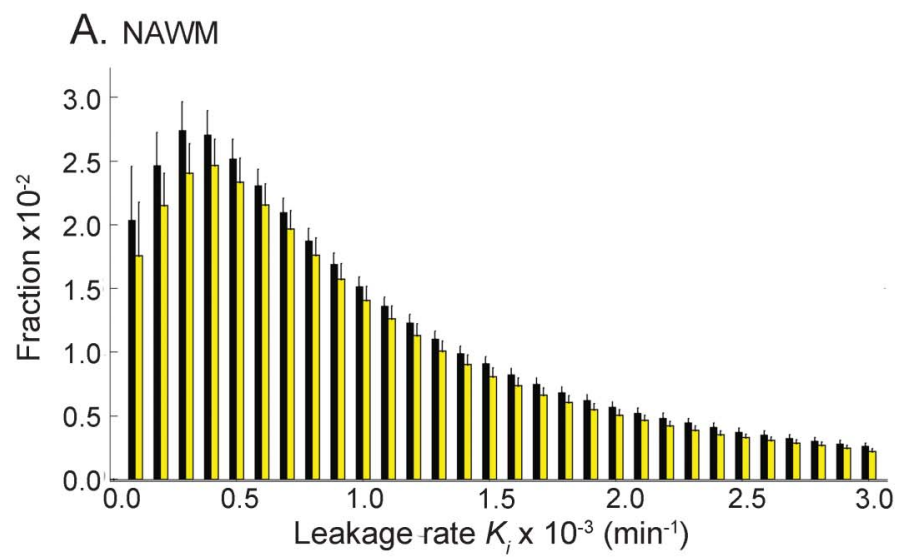

B. Cortex

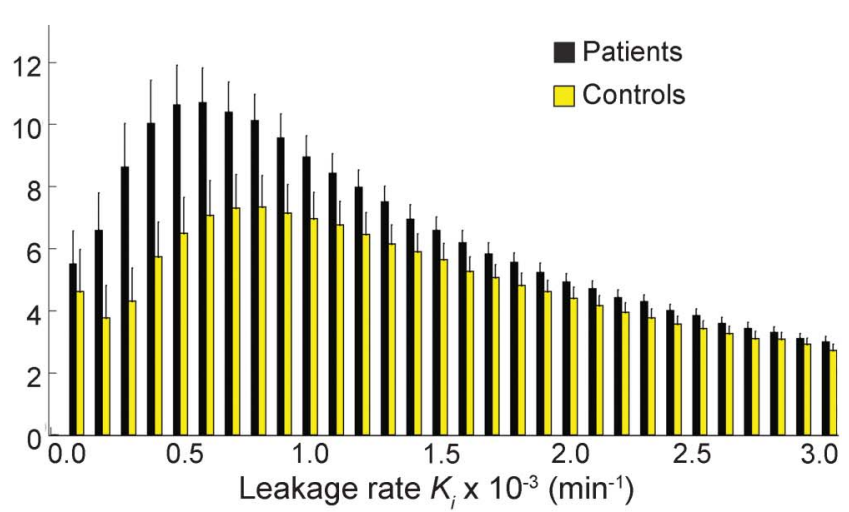

Group average noise-corrected leakage rate histograms in the NAWM (A) and cortical gray matter (B) for patients with cSVD (black) and controls (yellow). The $x$-axis shows the leakage rate $\left(\mathrm{K}_{\mathrm{i}}\right)$, the $\mathrm{y}$-axis represents the fraction (i.e., percentage divided by 100 ) of brain tissue with that leakage rate value. Note that patients reveal a higher leakage fraction of the relatively low leakage rate values. This results in a larger area under the curve: patients demonstrate a larger leakage volume. NAWM = normal-appearing white matter. 
leakage or volumetric changes in the microvasculature. In the current study, we set out to separate intravascular enhancement and BBB leakage by using the dual-time resolution scanning technique and adequate pharmacokinetic modeling. Recently, a longitudinal study found that regions with BBB leakage show minimal overlap over time, alluding to the dynamic nature of BBB leakage. ${ }^{28}$ We intend to perform longitudinal analyses in our cohort.

We found that patients with CSVD had a lower (although not significantly) blood plasma volume in all brain regions compared with controls. As blood plasma volume is related to cerebral perfusion, this observation is in line with the hypothesis that CSVD is associated with a reduction in cerebral blood flow or loss of autoregulation, causing chronic, diffuse ischemia in the long run. ${ }^{2}$ Further in vivo studies are needed to confirm the link between hypoperfusion and BBB leakage in CSVD.

We showed that hypercholesterolemia is significantly associated with lower leakage volume. As nearly all participants who met our criteria for hypercholesterolemia also use statins, this may reflect the hypothesis that statins improve endothelial function and stabilize the BBB. ${ }^{2,29}$

Leakage rate differed between lacunar stroke patients and patients with mVCI. Although we presume that the underlying pathophysiology in both groups is cSVD, differences may exist. The lacunar stroke group may be a more homogenous cSVD group compared with the mVCI group. Despite our selection criteria, it is possible that other pathophysiologic processes such as amyloid angiopathy or Alzheimer pathology coexist in some of the patients with $\mathrm{mVCI}$, affecting our findings and causing the differences in leakage rate.

Our study has several important strengths. First, we used clearly defined inclusion and exclusion criteria for patients with cSVD. This enabled us to have a well-represented spectrum of clinically overt patients with cSVD. Second, the age- and sexmatched controls enabled us to make reliable comparisons between the groups. Third, we optimized the MRI protocol by using 2 MRI sequences with 2 different temporal resolutions. Particularly the high temporal resolution during contrast injection enabled us to determine the intravascular component more accurately, which is a prerequisite for performing reliable pharmacokinetic modeling and specifically detecting the subtle leakage. ${ }^{22}$ Fourth, we applied pharmacokinetic modeling to provide quantitative data on $\mathrm{BBB}$ permeability for each voxel. This modeling is necessary for separating the leakage from intravascular contrast enhancement. ${ }^{23}$

A limitation of this study is that not the entire cerebrum was sampled during the fast sequence. However, the FOV covered important regions associated with small vessel disease pathology including the periventricular white (and gray) matter. ${ }^{30}$ The accuracy and reproducibility of our method is yet to be determined. However, it has recently been shown that the Patlak model is most suitable for determining subtle leakage, and our leakage rate values are comparable with leakage rate values found using a similar protocol in patient groups with subtle leakage. ${ }^{27,31}$

Our study provides more insight into BBB leakage in cSVD. It appears that BBB leakage is very subtle and more spatially extensive in patients with cSVD compared with age- and sex-matched controls without clinically overt cerebrovascular diseases. This underscores the generalized nature of CSVD and fits with the conceptual idea of spatially diffuse microvascular endothelial failure. In addition, our study provides a quantitative method to examine the magnitude and the spatial extent of subtle BBB leakage, establishing grounds for future longitudinal studies and possibly an important step towards further clarifying the role of $\mathrm{BBB}$ dysfunction in the pathogenesis of cSVD.

\section{AUTHOR CONTRIBUTIONS}

C. Eleana Zhang: study concept and design, acquisition of data, analysis and interpretation of data, writing manuscript. Sau May Wong: acquisition of data, analysis and interpretation of data, writing manuscript. Harm J. van de Haar: analysis of MRI data, critical revision of manuscript. Julie Staals: study concept and design, interpretation of data, critical revision of manuscript. Jacobus F.A. Jansen: interpretation of data, critical revision of manuscript. Cécile R.L.P.N. Jeukens: interpretation of data, critical revision of manuscript. Paul A.M. Hofman: analysis of MRI data, critical revision of manuscript. Robert J. van Oostenbrugge: study concept and design, interpretation of data, study supervision, critical revision of manuscript. Walter H. Backes: study design, interpretation of data, study supervision, critical revision of manuscript.

\section{ACKNOWLEDGMENT}

Marc Geerlings and Jos Slenter (Radiology and Nuclear Medicine, Maastricht University Medical Centre, the Netherlands) provided support in hardware and software. Martijn Wolters (Radiology and Nuclear Medicine, Maastricht University Medical Centre) contributed to the semiautomatic detection of white matter hyperintensities.

\section{STUDY FUNDING}

NWO (Netherlands Organisation for Scientific Research), grant 017.009.048; Hersenstichting, grant 2013(1)-195; Stichting de Weijerhorst foundation.

\section{DISCLOSURE}

The authors report no disclosures relevant to the manuscript. Go to Neurology.org for full disclosures.

Received February 21, 2016. Accepted in final form September 21, 2016.

\section{REFERENCES}

1. Wardlaw JM, Smith C, Dichgans M. Mechanisms of sporadic cerebral small vessel disease: insights from neuroimaging. Lancet Neurol 2013;12:483-497.

2. Pantoni L. Cerebral small vessel disease: from pathogenesis and clinical characteristics to therapeutic challenges. Lancet Neurol 2010;9:689-701. 
3. Pantoni L, Simoni M. Pathophysiology of cerebral small vessels in vascular cognitive impairment. Int Psychogeriatr 2003;15(suppl 1):59-65.

4. Skoog I, Wallin A, Fredman P, et al. A population study on blood-brain barrier function in 85-year-olds: relation to Alzheimer's disease and vascular dementia. Neurology 1998;50:966-971.

5. Pantoni L, Inzitari D, Pracucci G, et al. Cerebrospinal fluid proteins in patients with leucoaraiosis: possible abnormalities in blood-brain barrier function. J Neurol Sci 1993;115:125-131.

6. Wardlaw JM, Sandercock PA, Dennis MS, Starr J. Is breakdown of the blood-brain barrier responsible for lacunar stroke, leukoaraiosis, and dementia? Stroke 2003;34: 806-812.

7. Popescu BO, Toescu EC, Popescu LM, et al. Blood-brain barrier alterations in ageing and dementia. J Neurol Sci 2009;283:99-106.

8. Wardlaw JM, Doubal F, Armitage P, et al. Lacunar stroke is associated with diffuse blood-brain barrier dysfunction. Ann Neurol 2009;65:194-202.

9. Topakian R, Barrick TR, Howe FA, Markus HS. Bloodbrain barrier permeability is increased in normal-appearing white matter in patients with lacunar stroke and leucoaraiosis. J Neurol Neurosurg Psychiatry 2010;81:192-197.

10. Taheri S, Gasparovic C, Huisa BN, et al. Blood-brain barrier permeability abnormalities in vascular cognitive impairment. Stroke 2011;42:2158-2163.

11. Zhang CE, van Raak EP, Rouhl RP, et al. Metabolic syndrome relates to lacunar stroke without white matter lesions: a study in first-ever lacunar stroke patients. Cerebrovasc Dis 2010;29:503-507.

12. Wardlaw JM, Smith EE, Biessels GJ, et al. Neuroimaging standards for research into small vessel disease and its contribution to ageing and neurodegeneration. Lancet Neurol 2013;12:822-838.

13. Barnett HJ, Barnes RW, Clagett GP, Ferguson GG, Robertson JT, Walker PM. Symptomatic carotid artery stenosis: a solvable problem: North American Symptomatic Carotid Endarterectomy Trial. Stroke 1992;23:1048-1053.

14. Yang Y, Rosenberg GA. Blood-brain barrier breakdown in acute and chronic cerebrovascular disease. Stroke 2011;42: 3323-3328.

15. Gorelick PB, Scuteri A, Black SE, et al. Vascular contributions to cognitive impairment and dementia: a statement for healthcare professionals from the American Heart Association/American Stroke Association. Stroke 2011; 42:2672-2713.

16. Fazekas F, Chawluk JB, Alavi A, Hurtig HI, Zimmerman RA. MR signal abnormalities at $1.5 \mathrm{~T}$ in Alzheimer's dementia and normal aging. AJR Am J Roentgenol 1987;149: 351-356.
17. van de Haar HJ, Burgmans S, Jansen JF, et al. Blood-brain barrier leakage in patients with early Alzheimer disease. Radiology 2016;281:527-535.

18. Larsson HB, Courivaud F, Rostrup E, Hansen AE. Measurement of brain perfusion, blood volume, and blood-brain barrier permeability, using dynamic contrast-enhanced $\mathrm{T}$ (1)-weighted MRI at 3 tesla. Magn Reson Med 2009;62: 1270-1281.

19. Fischl B. FreeSurfer. Neuroimage 2012;62:774-781.

20. de Boer R, Vrooman HA, van der Lijn F, et al. White matter lesion extension to automatic brain tissue segmentation on MRI. Neuroimage 2009;45:1151-1161.

21. Jenkinson M, Bannister P, Brady M, Smith S. Improved optimization for the robust and accurate linear registration and motion correction of brain images. Neuroimage 2002; $17: 825-841$.

22. Lavini C, Verhoeff JJ. Reproducibility of the gadolinium concentration measurements and of the fitting parameters of the vascular input function in the superior sagittal sinus in a patient population. Magn Reson Imaging 2010;28:1420-1430.

23. Patlak CS, Blasberg RG. Graphical evaluation of blood-tobrain transfer constants from multiple-time uptake data: generalizations. J Cereb Blood Flow Metab 1985;5:584-590.

24. Benjamini Y, Drai D, Elmer G, Kafkafi N, Golani I. Controlling the false discovery rate in behavior genetics research. Behav Brain Res 2001;125:279-284.

25. Young VG, Halliday GM, Kril JJ. Neuropathologic correlates of white matter hyperintensities. Neurology 2008;71: 804-811.

26. Bridges LR, Andoh J, Lawrence AJ, et al. Blood-brain barrier dysfunction and cerebral small vessel disease (arteriolosclerosis) in brains of older people. J Neuropathol Exp Neurol 2014;73:1026-1033.

27. Montagne A, Barnes SR, Sweeney MD, et al. Blood-brain barrier breakdown in the aging human hippocampus. Neuron 2015;85:296-302.

28. Huisa BN, Caprihan A, Thompson J, Prestopnik J, Qualls CR, Rosenberg GA. Long-term blood-brain barrier permeability changes in Binswanger disease. Stroke 2015; 46:2413-2418.

29. Giannopoulos S, Katsanos AH, Tsivgoulis G, Marshall RS. Statins and cerebral hemodynamics. J Cereb Blood Flow Metab 2012;32:1973-1976.

30. Duering M, Csanadi E, Gesierich B, et al. Incident lacunes preferentially localize to the edge of white matter hyperintensities: insights into the pathophysiology of cerebral small vessel disease. Brain 2013;136:2717-2726.

31. Barnes SR, Ng TS, Montagne A, Law M, Zlokovic BV, Jacobs RE. Optimal acquisition and modeling parameters for accurate assessment of low Ktrans blood-brain barrier permeability using dynamic contrast-enhanced MRI. Magn Reson Med 2016;75:1967-1977. 